\title{
LOOMing possibilities: Learning APA style the self-paced way
}

\section{Carra Leah Hood ${ }^{1}$}

I teach required, first-year writing courses at Richard Stockton College of New Jersey. Like many other teachers of first-year writing, I am used to complaints, grumblings from students (about my writing assignments), from faculty colleagues (about the quality of students' writing in their courses), and from employers (about their need for employees who can write well).

Faculty members frequently point to students' lack of preparedness for writing literature reviews in social science majors (McDonald, 2012). Until recently, very few first-year writing teachers at Stockton introduced students to APA research, writing, and citation style. That practice has changed over the past 8 years, and now, as is common practice in many first-year writing programs, students at Stockton receive an introduction to APA style in their first-year seminar, first-year writing course, or both. A collective commitment among first-year writing teachers to provide students with instruction in APA in-text and reference page citation forms did not really address the substance of faculty members' complaints: when students enter research courses in their majors, many do not understand the APA and social science concept of research and have no prior experience writing or reading literature reviews.

To address this, I created a first-year writing course, Introduction to Research that, although open to all students regardless of major, appeals primarily to social science majors. The course offers students who take it an opportunity to study APA research and writing style and to conduct and write up empirical research studies. The first semester it was offered, spring 2007, I taught 2 sections; it was not offered in the fall 2007. Since then, however, students can choose from multiple sections of Introduction to Research in both fall and spring semesters. This course has become a popular course among students, faculty members, and advisors. However, Introduction to Research is only one course; not all students who might benefit from the course have a chance to take it.

To reach those students, I facilitated a free, three-hour APA research and writing workshop one Saturday each semester. The workshop turned into two workshops and, then, turned into a month-long hybrid course offered through Continuing Education. A faculty member in the School of Business and I voluntarily co-facilitated the course each semester. When that faculty member left for a position in New Mexico, I taught the hybrid course for two more semesters.

In the fall 2013, in an effort to distribute the APA course more broadly, I met with the information technology department about recasting the hybrid APA course as a MOOC. We decided against that, though, as the student population for the course had been largely matriculated Stockton undergraduate juniors and seniors or graduate students, rather than a dispersed, global student population more suited for a MOOC. At that point, we worked to transform the month-long APA course into a Stockton-based "floating" online module or LOOM, Local Open Online Module. Any faculty member can import the LOOM into an existing course and fully customize the lessons. Alternatively, students can use the LOOM as a resource

\footnotetext{
${ }^{1}$ Carra Leah Hood is Associate Professor of Writing, Director of Essential Learning Outcomes, and as of July 1, 2014, Interim Assistant Provost for Programs and Planning at Richard Stockton College of New Jersey. The ideas in this essay were shared at the 2014 annual New Jersey College English Association conference at Seton Hall University.
} 
or as a self-paced learning opportunity. We completed that project and distributed the LOOM across the campus in February 2014.

Now, all faculty members can access the LOOM from among the shared course files in Blackboard, our learning management system (LMS), and import it into any course space on his/her Blackboard page. Once a faculty member imports the LOOM, he/she can modify it to fit a particular academic discipline and course content. A faculty member can use the LOOM in the way they might use a textbook in an existing course, post the LOOM to Blackboard as a resource for students, pick and choose which sections of the LOOM to use in a given course, or require students to complete the LOOM prior to the beginning of a particular course. In the latter case, results of the pre-test or the results of the pre and post-test can help a faculty member pitch any additional or reinforcing APA instruction in his/her course.

\section{Contents of the LOOM}

The LOOM begins with a note to faculty, offering some ideas for ways a faculty member can integrate the LOOM into an existing course. Since distributing the LOOM, faculty members in the School of Education and the School of Social and Behavioral Sciences have discussed adding the LOOM to courses that require research and writing. The Social Work and Criminal Justice Programs, for instance, are considering requiring the LOOM for undergraduate majors and Master's students. The Director of the Writing Center has incorporated the LOOM to the course that prepares student tutors. Because prospective tutors complete the course and have access to the lessons and resources after the course ends, they can refer to individual lessons or pass on particular resources during a tutoring session.

In the note to faculty, I suggest that faculty members customize the LOOM, in particular, adding discipline-specific examples of published articles written in APA form. The LOOM currently contains examples of articles in APA style from various disciplines, corresponding to the majors of students who took the hybrid version of the LOOM. Instead of using those examples, a number of faculty members in the School of Business have discussed collaborating to replace those examples with articles from business journals; that way, business faculty members who use the LOOM can share business-relevant APA article examples with students in their courses.

The LOOM was distributed to staff and administrators as well as to faculty. Recently, a staff person from the School of General Studies informed me that she is working her way through the LOOM in preparation to begin graduate school in the fall 2014.

When students enter the LOOM, they are prompted to take a pre-test. They do not have access to any other course materials until they complete the pre-test and click the submit button. A student does not receive a certificate of completion until after submitting the post-test. The pre and post-test consist of twenty-five multiple choice and true/false questions. The questions are randomized, and each has an explanation for wrong answers and for right answers as well as a notation about where to go in the Publication Manual of the American Psychological Association (chapter/page number) for fuller description; consequently, students can learn as they move through the questions. Faculty members who import the LOOM into their courses can assess students' learning from pre to post-test, too, and use the results to make any necessary adjustments to in-class instruction or to LOOM content.

After submitting the pre-test, a student can access the other course materials. The LOOM contains three assignments: 1) a references page, 2) a literature review, and 3) an annotated 
bibliography. I created these assignments because they were common assignments among the students who attended the Saturday workshops or took the hybrid course.

Following the assignment descriptions are the course syllabus, a video overview, a folder containing APA resources, and twelve lessons. The lessons range from "What is APA Style?" to "Punctuation," "Information Literacy," "Headings," and "Plagiarism." Each lesson provides ample examples of ways to use the principle or practice in research and writing.

\section{Benefits of a LOOM}

The LOOM has all the benefits of a MOOC and none of the most commonly-cited disadvantages (Chen, Barnett, \& Stephens, 2013; Dominique, 2014; Gerth, 2012; University of the People, 2014).

1. The LOOM is open, free, online, customizable, accessible to any faculty member who wants to use it, easily updated, and self-contained.

2. Because faculty members import the LOOM into existing courses, students can have faculty and course support as they move through the lessons (Coffin, 2013).

3. In addition, writing tutors complete the LOOM, which means students taking the LOOM can seek peer guidance, too, if they have questions or confront any difficulties.

4. Like some MOOC assignments, the pre and post-test is machine graded. However, students taking the LOOM in the context of a Stockton course have access to their teachers who can answer particular questions related to the tests (Coffin, 2013). Unlike the practice in MOOCs, faculty members using the LOOM grade students' writing assignments.

5. Unlike MOOCs, the LOOM does not attract tens of thousands of virtual students, many of whom do not engage with group members or in discussions; the students who take the LOOM are Stockton students taking Stockton courses.

6. The LOOM creates an opportunity for faculty members to collaborate for the benefit of students. At Stockton, co-teaching occurs infrequently, and there is no incentive for doing so; however, the LOOM facilitates pedagogical and content sharing among faculty members. If LOOMs become a more visible part of the Stockton landscape than they currently are, I can imagine a single course importing two or three LOOMs; in this way, LOOMs could offer a model for courses that regularly involve multiple teachers in content delivery.

7. The LOOM can be imported into more than a single course in a student's schedule in one or more semesters while they attend Stockton. Consequently, students can have access to LOOM resources over time, thus, leading to reinforced fluency with APA research and writing style.

8. The LOOM can be shared more broadly, outside of Stockton, through the Blackboard community, and because it can be exported in html, the LOOM can also be viewed on the Internet.

Since distributing my APA LOOM, I have considered creating others. As learning modules, LOOMs can exist to provide instruction in the types of skills or content, such as APA research and citation style, that oftentimes fall through the cracks in the curriculum (Hollands \& Tirthali, 2014, p. 169). I have been in conversations with math professors distressed because students in basic and pre-calculus math courses do not understand the number line, a foundational principle typically not covered in those courses; this topic is just waiting for a 
Hood, C.L.

LOOM. Most of the writing faculty members at Stockton no longer teach grammar and punctuation; a LOOM could aid students struggling with those skills. Students in teacher prep frequently have difficulty passing the PRAXIS exam in English; I can imagine a LOOM that guides students in English-language literary history, a necessary kind of knowledge for students preparing to take the PRAXIS II English subject test.

I can't say that LOOMs are the future of higher education, but they certainly offer a means to employ digital technologies in a new way that can fill in curricular gaps, help students through some difficult learning hurdles, and as a result, play a part in enhancing students' overall success in college.

\section{References}

Chen, X., Barnett, D. R., \& Stephens, C. (2013). Fad or future: The advantages and challenges of massive open online courses (MOOCs). Paper presented at the Research-to-Practice Conference in Adult and Higher Education, Lindenwood University, St. Charles, Missouri. Retrieved from http://www.lindenwood.edu/r2p/docs/ChenBarnettStephens.pdf

Coffin, D. A. (2013). MOOCs and me. Journal of Teaching and Learning with Technology, 2(2), 1-4. Retrieved from http://jotlt.indiana.edu/article/view/3893

Dominique, A. (2014, January 22). The pros and cons of massive open online courses. $Q A$ Education. Retrieved from http://www.qaeducation.co.uk/the-future-of-online-learning-ismassive/

Gerth, M. (2012, November 12). Weighing the pros and cons of massive open online courses (MOOCs). Technapex. Retrieved from http://www.technapex.com/2012/11/weighing-the-prosand-cons-of-massive-open-online-courses-moocs/

Hollands, F. M., \& Tirthali, D. (2014). MOOCs: Expectation and reality. Retrieved from http://cbcse.org/wordpress/wp-content/uploads/2014/05/MOOCs_Expectations_and_Reality.pdf

McDonald, K. E. (2011). Teaching the $6^{\text {th }}$ edition of APA style writing in counselor education. Journal of Counselor Preparation and Supervision, 3(2), 124-145. Retrieved from http://repository.wcsu.edu/cgi/viewcontent.cgi?article $=1031 \&$ context $=$ jcps

University of the People. (2014). Are MOOCs for everyone? Retrieved from http://uopeople.edu/articles/moocs_free_education 